\title{
Sexual Dimorphism in the Brain of the Monogamous California Mouse (Peromyscus californicus)
}

\author{
Katharine L. Campi Chelsea E. Jameson Brian C. Trainor \\ Department of Psychology and Center for Neuroscience, University of California Davis, Davis, Calif., USA
}

\begin{abstract}
Key Words
Sexual dimorphism - California mouse - Ventral tegmental area - Bed nucleus of the stria terminalis - Medial amygdala
\end{abstract}

\begin{abstract}
Sex differences in behavior and morphology are usually assumed to be stronger in polygynous species compared to monogamous species. A few brain structures have been identified as sexually dimorphic in polygynous rodent species, but it is less clear whether these differences persist in monogamous species. California mice are among the $5 \%$ or less of mammals that are considered to be monogamous and as such provide an ideal model to examine sexual dimorphism in neuroanatomy. In the present study we compared the volume of hypothalamic- and limbic-associated regions in female and male California mice for sexual dimorphism. We also used tyrosine hydroxylase (TH) immunohistochemistry to compare the number of dopamine neurons in the ventral tegmental area (VTA) in female and male California mice. Additionally, tract tracing was used to accurately delineate the boundaries of the VTA. The total volume of the sexually dimorphic nucleus of the preoptic area (SDN-POA), the principal nucleus of the bed nucleus of the stria terminalis (BNST), and the posterodorsal medial amygdala (MEA) was larger in males compared to females. In the SDN-POA we found that the magnitude of sex differences in the California mouse were intermediate between the large differences observed in promiscuous meadow voles and rats and the ab-
\end{abstract}

sence of significant differences in monogamous prairie voles. However, the magnitude of sex differences in MEA and the BNST were comparable to polygynous species. No sex differences were observed in the volume of the whole brain, the VTA, the nucleus accumbens or the number of TH-ir neurons in the VTA. These data show that despite a monogamous social organization, sexual dimorphisms that have been reported in polygynous rodents extend to California mice. Our data suggest that sex differences in brain structures such as the SDN-POA persist across species with different social organizations and may be an evolutionarily conserved characteristic of mammalian brains.

(c) 2013 S. Karger AG, Basel

\section{Introduction}

Sexual selection is an important factor in the generation of sex differences in morphology and behavior. Intrasexual competition or mating preferences can result in the development of extreme ornaments or behavioral displays, which are often sexually dimorphic. Sexual selection is also thought to have important effects on brain morphology. However, the functional significance of sexual dimorphism in the brain has been debated [Sodersten, 1987; Cooke et al., Davis 1998; De Vries and Boyle, 1998; De Vries and Sodersten, 2009; Kelley, 1986]. On the one hand, sexual dimorphism in brain structure can be strongly linked with sex differences in behavior. In song-

\section{KARGER}

E-Mail karger@karger.com

www.karger.com/bbe
(C) 2013 S. Karger AG, Basel

0006-8977/13/0814-0236\$38.00/0
Katharine Campi

Psychology Department, University of California, Davis

1 Shields Avenue

Davis, CA 95616 (USA)

E-Mail klcampi@ucdavis.edu 
Table 1. Sexual dimorphism by area, type and mating system

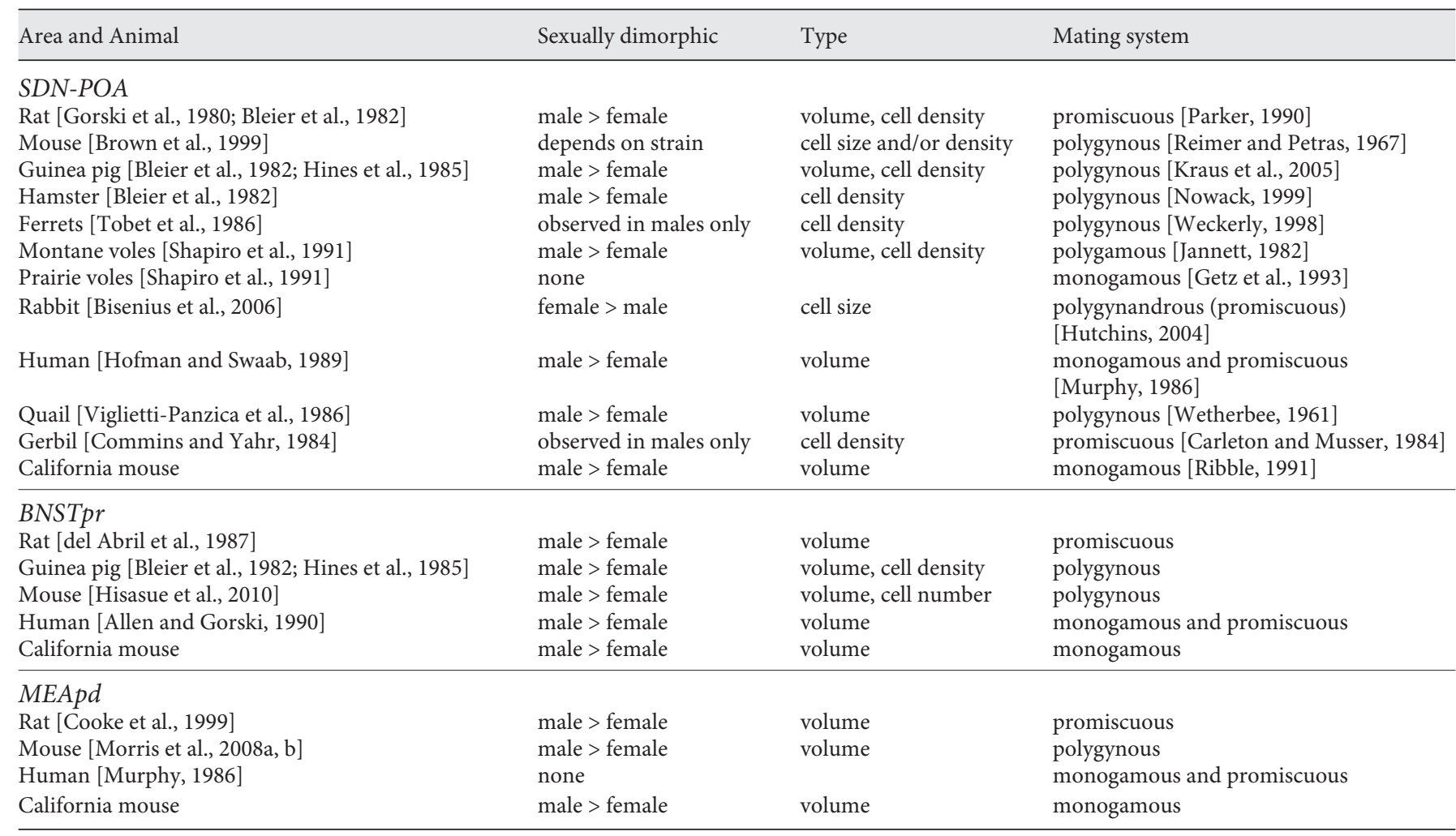

birds, striking sexual dimorphisms in the song control system are observed in species in which only males sing [Wade and Arnold, 2004]. On the other hand, there is evidence that sexual dimorphism in brain structure may reflect different mechanisms for achieving a common behavioral output. For example, in prairie voles a sexual dimorphism in the vasopressin system promotes male parental behavior [Wang et al., 1994]. Because the only difference between male and female parental behavior in this species is lactation, it has been argued that sex differences in brain structure prevent sex differences in parental behavior in prairie voles [De Vries and Boyle, 1998]. Thus, sexual dimorphism in brain structure can underlie both behavioral differences and similarities between males and females.

Most sex differences in brain morphology are observed within a network of hypothalamic and limbic brain regions often referred to as the social behavior circuit [Newman, 1999; Goodson, 2005]. The sexually dimorphic nucleus of the preoptic area (SDN-POA) is the most wellknown sexual dimorphism in mammalian brains. Initially described in rats, males have more cells and increased cell density in the SDN-POA than females [Gorski et al., 1980]. The SDN-POA is larger by volume and/or cell density or size in males in a wide array of species (table 1; note the exception of rabbits). Male copulatory behavior typically consists of different motor patterns than female copulatory behavior, and it was hypothesized that sexual dimorphism in the SDN-POA contributed to these differences. In adults, lesions of the SDN-POA disrupt male sexual behavior in virgin rats [De Jonge et al., 1989] but not sexually experienced rats [Arendash and Gorski, 1983]. Intriguingly, the SDN-POA has been linked instead to mating preferences in rats [Paredes et al., 1998], ferrets [Paredes and Baum, 1995] and sheep [Roselli et al., 2004]. In mating preference tests, males of all three of these species typically prefer females. However, about $25 \%$ of rams prefer to mount other rams instead of ewes [Alexander et al., 2011], and this preference is linked to smaller volume of the SDN-POA [Roselli et al., 2004]. In rats [Houtsmuller et al., 1994] and ferrets [Paredes and Baum, 1995], the hormonal milieu during development of the SDN-POA affects sexual partner preference as well, such that rats treated with an aromatase inhibitor pre- and neonatally or fer- 
rets with neonatal medial preoptic area lesions exhibited a preference for males over females. Another aspect of mating preferences is partner preference. In polygynous species such as Rattus, individuals tend to mate with several partners whereas in monogamous species long-term pair bonds are formed with an individual mating partner [Carter et al., 1995]. In Mus and Rattus, the SDN-POA is roughly 2-3 times larger in males than females whereas in socially monogamous prairie voles the SDN-POA is not significantly larger at approximately 1.4 times the size in males [Shapiro et al., 1991]. Recent pharmacological studies have demonstrated that the mesolimbic dopamine system plays a critical role in the formation of partner preferences [Aragona et al., 2003].

The mesolimbic dopamine system encompasses populations of dopaminergic neurons in the ventral tegmental area (VTA) that project to forebrain nuclei including the nucleus accumbens core (NAc) and frontal cortex (FC) as well as the bed nucleus of the stria terminalis (BNST) and amygdala. Indeed, it has been proposed that the social behavior network interacts with the mesolimbic dopamine system to form a social decision-making network [O'Connell and Hofmann, 2011, 2012]. Studies of the mesolimbic dopamine system in rats report that the overall size of the VTA is larger in females [McArthur et al., 2007] and that females have more large spines than males in the NAc [Forlano and Woolley, 2010; Wissman et al., 2012]. Interestingly, females also have a larger FC than males in two species of Microtus voles, although this sex difference was absent in two species of Peromyscus mice [Kingsbury et al., 2012]. However, in promiscuous voles and Peromyscus, FC size is larger compared to closely related species that are socially monogamous. These data suggest that individual nodes in the social decision-making network can vary independently of each other.

The majority of studies examining sex differences in brain structure have focused on domesticated rats or mice, which have similar polygynous social organizations [Berdoy and Drickhamer, 2007]. Although the sex differences in the size of the BNST or medial amygdala (MEA) have not been reported in monogamous species, there is strong evidence for sex differences in the chemoarchitecture of these nuclei [Cushing and Wynne-Edwards, 2006; Northcutt et al., 2007; Holmes et al., 2008; Wu et al., 2009]. To our knowledge, no study has examined whether sex differences exist in the mesolimbic dopamine system nuclei in a monogamous species. Here we examine sex differences in morphological and histological components of the social behavior network and mesolimbic system in the monogamous California mouse (Peromyscus californicus). Males and females of this species form monogamous breeding pairs [Ribble, 1991] and defend joint territories [Ribble and Salvioni, 1990], which is unique among mammals as only $3 \%$ of mammals are considered to be monogamous [Carter et al., 1995]. The relatively unique natural history of California mice has contributed to its emergence as an important species for studying many aspects of behavior including development [BesterMeredith and Marler, 2003; Frazier et al., 2006], parental behavior [de Jong et al., 2009; Lambert et al., 2011], aggression [Fuxjager and Marler, 2010; Silva et al., 2010; Trainor et al., 2010b], mating preferences [Gleason et al., 2012], communication [Kalcounis-Rueppell et al., 2010] and stress [Trainor et al., 2010a; Chauke et al., 2011; Trainor et al., 2011]. Although immunostaining studies have compared the chemoarchitecture of male and female California mice, there has been little quantification of the size of nuclei within the social behavior network or mesolimbic dopamine system [but see Gubernick et al., 1993]. We compared the volumes of the whole brain, NAc, BNST, BNST posterior dorsal division (BNSTpr), BNST anterior medial division (BNSTam), VTA, MEA, MEA posterior dorsal division (MEApd) and SDN-POA in sexually mature male and female California mice. We also used immunohistochemistry to compare the number of tyrosine hydroxylase (TH)-positive cells in the VTA in male and female California mice. Based largely on previous observations in monogamous prairie voles, we predicted that sexual dimorphism in the SDN-POA, BNSTpr and MEApd would be modest compared to other promiscuous species of rodents. While this prediction was correct for the SDN-POA, we observed that sexual dimorphism in the BNSTpr and MEApd was comparable to what has been observed in promiscuous species of rodents. Our results provide interesting insights into the relationship between social organization and sexual dimorphism in the brain.

\section{Materials and Methods}

Morphometric and histological comparisons were made using 10 whole brains from 5 male and 5 female California mice (P. californicus). For a complete listing of body and brain weights, brain volume and \% brain to body ratio for each animal see table 2 . Male and female mice ranged from 17 to 19 weeks in age. Two additional adult male California mice were used for tracer injections in order to differentiate substantia nigra pars compacta $(\mathrm{SNc})$ from the VTA. All mice were from our breeding colony, lived on corn cob bedding, were fed Harlan Teklad 2016 Global diet and had a long day light cycle (16L:8D). All procedures were approved by the Internal Animal Care and Use Committee and conformed to NIH guidelines. 
Table 2. Brain and body weight information for individual cases

\begin{tabular}{llllll}
\hline Animal & Sex & $\begin{array}{l}\text { Body } \\
\text { weight, g }\end{array}$ & $\begin{array}{l}\text { Brain } \\
\text { weight, g }\end{array}$ & $\begin{array}{l}\text { Brain } \\
\text { volume, } \\
\mathrm{mm}^{3}\end{array}$ & $\begin{array}{l}\text { \% Brain } \\
\text { to body } \\
\text { ratio }\end{array}$ \\
\hline DM 1282 & female & 32.73 & 0.89 & 906 & 2.71 \\
DM 1283 & female & 31.87 & 0.80 & 804 & 2.52 \\
DM 1287 & female & 31.74 & 0.78 & 792 & 2.46 \\
DM 1290 & female & 37.91 & 0.83 & 860 & 2.20 \\
DM 1297 & female & 28.5 & 0.78 & 778 & 2.75 \\
DM 1276 & male & 29.29 & 0.87 & 856 & 2.98 \\
DM 1279 & male & 28.85 & 0.67 & 664 & 2.31 \\
DM 1280 & male & 27.96 & 0.76 & 748 & 2.71 \\
DM 1295 & male & 32.93 & 0.78 & 782 & 2.37 \\
DM 1298 & male & 30.15 & 0.89 & 884 & 2.95 \\
\hline
\end{tabular}

\section{Morphometric and Histological Processing}

Animals were euthanized through isoflurane induction (5\%) for $90 \mathrm{~s}$ followed by rapid decapitation. The brain was extracted from the skull and fixed in a 5\% solution of acrolein in phosphate-buffered saline (PBS) for $24 \mathrm{~h}$. Brains were then blocked behind the cerebellum. Care was taken to block brains of all animals at the same location, immediately caudal to the cerebellum. After blocking, weight and volume measurements were taken. Volume measurements were made by using fluid displacement, which relies on the Archimedean principle of fluid displacement based on the 'suspension technique' described by Hughes [2005; see also Scherle, 1970; Weibel, 1979; Howard and Reed, 2005; Karlen and Krubitzer, 2006, 2009]. Using this method the volume of the object suspended in a fluid is equal to the weight of the fluid displaced by the suspended object divided by the specific gravity of the fluid. A beaker of $0.9 \%$ normal saline (specific gravity $=1.0048$ ) was placed on a laboratory balance (Denver Instrument; $d= \pm 0.01 \mathrm{~g}$ ) and a plastic mesh basket was suspended below the surface of the saline while not touching the sides or bottom of the beaker. The balance was tared and the brain was placed in the basket. The weight was recorded and repeated 5 times for each brain. To ensure accuracy of the measurement an average of the 5 measurements was used to calculate the final volume shown in table 2 . The brains were immersed in $20 \%$ sucrose overnight, frozen and sectioned at $40 \mu \mathrm{m}$ on a cryostat coronally from just posterior to the olfactory bulbs to halfway through the hippocampus. The brain was then removed from the chuck and replaced dorsal side down on the chuck and sectioned horizontally for visualization of the VTA. Brain sections were then divided into a one-in-two series for processing. One series of coronal and horizontal sections was mounted on gelatincoated slides and stained using cresyl violet, and a second set of coronal and horizontal sections was processed for TH immunohistochemically. Briefly, sections were washed 3 times with PBS and blocked in $10 \%$ rabbit serum and $3 \%$ hydrogen peroxide in PBS. Sections were incubated successively with sheep polyclonal antiTH antibody (1:600, Millipore AB 1542), rabbit biotinylated-conjugated polyclonal anti-sheep antibody (1:500, Vector BA-6000), and horseradish peroxidase-conjugated avidin/biotin complex (Vectastain elite ABC kit, Vector Laboratories, Burlingame, Calif., USA). Sections were then exposed to diaminobenzidine (Vector
Laboratories) for detection. All sections were dehydrated in ethanol, cleared in Histoclear (National Diagnostics, Atlanta, Ga., USA) and coverslipped with permount (Fisher Scientific SP15-500).

\section{Tracer Injections}

The neuroanatomical tracer injections were performed under standard sterile conditions. At the beginning of these experiments, the animals were anesthetized and maintained with isoflurane anesthesia. Once anesthetized, the skin was cut, the skull was exposed and a burr hole drilled at the stereotaxically (anterior-posterior: $0.51 \mathrm{~mm}$, medial-lateral: $\pm 1.1 \mathrm{~mm}$, dorsal-ventral: $3.0 \mathrm{~mm}$ ) defined position for the dorsal striatum. These coordinates were found empirically as there is no stereotaxic atlas for the California mouse. A $10 \%$ solution of 10,000 molecular weight each of either biotinylated dextran amine (BDA) or fluoro-ruby (FR; Invitrogen, Carlsbad, Calif., USA) was injected with a calibrated Hamilton syringe (Hamilton Co., Reno, Nev., USA). Approximately $0.3 \mu \mathrm{l}$ of the tracer was injected. One week was allowed for tracer transport. Animals were euthanized with a lethal dose of sodium pentobarbital $(250 \mathrm{mg} / \mathrm{kg})$ and perfused transcardially with $0.9 \%$ saline followed by $4 \%$ paraformaldehyde in $0.1 \mathrm{M}$ phosphate buffer ( $\mathrm{pH} 7.4$ ). The brains were extracted and immersed in $20 \%$ sucrose overnight, frozen and sectioned at a $40-\mu \mathrm{m}$ thickness on a cryostat in the horizontal plane. Sections were split into a one-in-three series for processing. One series of sections was immediately mounted on gelatin-coated slides and used for examination of connections labeled with FR, a second series of sections was processed for connections labeled using BDA and a third series of sections was stained using cresyl violet. FR labeling was visualized using a Zeiss Axioimager and Zeiss filter set 43 Excitation 545/25; Emission BP $605 / 70$. BDA labeling was visualized with horseradish peroxidaseconjugated avidin/biotin complex (Vectastain elite ABC kit, Vector Laboratories). Sections were then exposed to diaminobenzidine for detection and viewed on the same microscope as above under bright field illumination. All sections were dehydrated in ethanol, cleared in Histoclear (National Diagnostics) and coverslipped with permount (Fisher Scientific SP15-500).

\section{Brain and Body Comparison Measures}

The brain and body weights were measured in each animal and the brain weight/body weight ratio was calculated for individual animals. Group averages were then calculated for each measure. Brain weight, body weight, brain volume and brain-to-body weight percentage were then compared across groups using independent $\mathrm{t}$ tests for female and male comparisons.

\section{Reconstruction and Data Analysis}

Architectonic boundaries of each brain region of interest from sections stained with cresyl violet were drawn from photomicrographs using Adobe Illustrator (version CS2). The volume of each region of interest was calculated using the Cavalieri method [Mayhew et al., 1990; Howard and Reed, 2005; Karlen and Krubitzer, 2006, 2009] as determined by the formula:

$$
V=(T \times A 1)+(T \times A 2)+\ldots+(T \times A n)=T \sum_{i=1}^{n} A i,
$$

where $V$ is the total volume of the nucleus, $T$ is the thickness of the section ( $80 \mu \mathrm{m}$ - to account for use of alternate sections) and $A i$ is the cross-sectional area of the object seen on the $i$-th section. We did not adjust the calculated volumes for tissue shrinkage or 
Fig. 1. Representative photomicrographs of $40-\mu \mathrm{m}$ coronal sections of the SDN-POA stained with cresyl violet in female (a) and male (b) California mice. The SDN-POA is significantly larger in males compared to females $(p<0.05)$. Thin solid lines indicate the boundary of the SDN-POA. Scale bars $=500 \mu \mathrm{m}$.

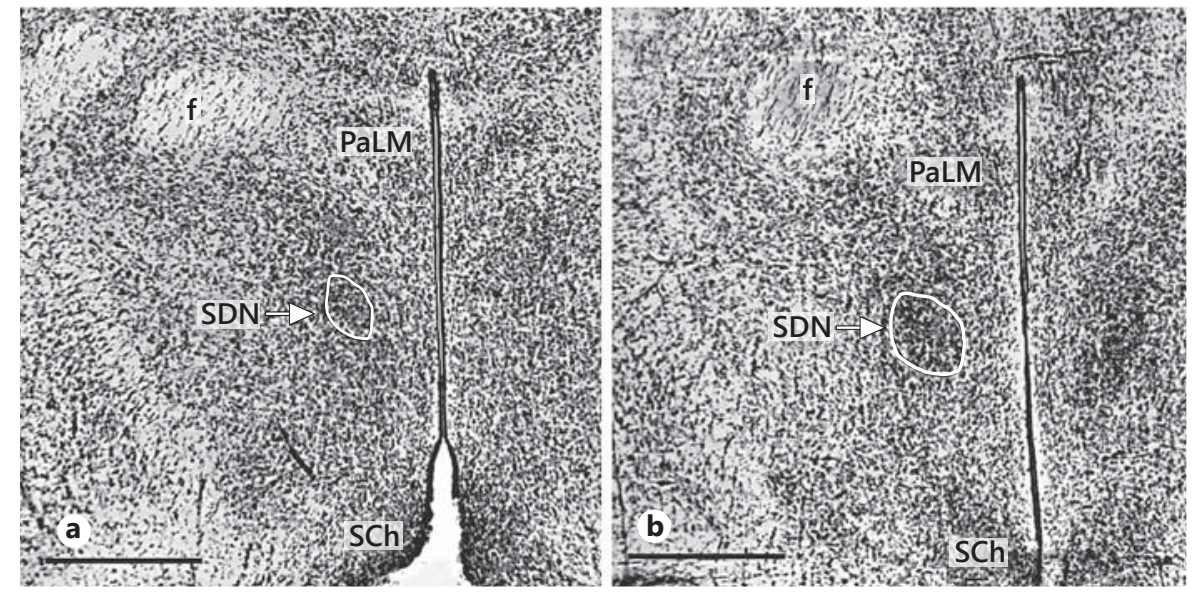

section compression as we were interested in the difference between groups and the brains from both groups underwent the same histological processing.

For cell counting in the VTA, TH-ir-positive cells were counted in each section through the entire one-in-two series of sections reacted for TH. All TH-ir-positive cells within the boundaries delineating VTA were counted. As can be observed in online supplementary figure 1 (see www.karger.com/doi/10.1159/000353260 for all online suppl. material), TH-ir cells are readily distinguished from background in this representative section. Cell counts from individual sections were then summed for a total cell count for each case. Individual case cell counts were then averaged by group and then compared across groups using independent $t$ tests for female and male comparisons. Adjustments to the contrast and brightness of photomicrographs were made using Adobe Photoshop (CS2 version).

\section{Determination of Nuclei and Volume Observations}

Atlases of mouse and rat brain were used in order to identify the boundaries of nuclei and areas delineated here because there is not an atlas of the California mouse brain, which is larger than a mouse brain but smaller than a rat brain [Paxinos and Watson, 1982; Franklin and Paxinos, 2007; Paxinos et al., 2008]. The SDNPOA is readily distinguished as an oval cell-dense region of the POA (fig. 1). The SDN-POA is located midway between the anterior commissure (AC) dorsally and the suprachiasmatic nucleus ventrally and just lateral to the third ventricle. The volume of the SDN-POA ranged from 0.01 to $0.05 \mathrm{~mm}^{3}$ on each side and together account for a mean of $0.05 \%$ of total brain volume.

The anatomy of the BNST is quite complex and over several decades has been subdivided into between 2 and 12 different parts [Ju and Swanson, 1989]. We used nomenclature from Ju and Swanson [1989] to identify subregions of the BNST. The BNSTam can be delineated by densely packed cells that wrap the AC (fig. 2a). As the AC decussates, the BNSTam can be delineated as the medial part of the bilateral triangular wedges above the lateral one third of the AC (fig. 2b). The principal nucleus or the BNST (BNSTpr) and BNSTam were also measured separately as these subregions have been demonstrated to be sexually dimorphic (fig. 2c, d) [Hines et al., 1992; Alheid et al., 1998; Cooke et al., 1999; ] and to contain hormonally responsive neurons [Cushing and
Wynne-Edwards, 2006; Trainor et al., 2007]. The volume of the BNST ranged from 1.24 to $1.66 \mathrm{~mm}^{3}$ on each side and together account for a mean of $0.36 \%$ of total brain volume. The volume of BNST pr ranged from 0.1 to $0.2 \mathrm{~mm}^{3}$ on each side and together account for a mean of $0.04 \%$ of total brain volume. The volume of BNSTam ranged from 0.17 to $0.25 \mathrm{~mm}^{3}$ on each side and together account for a mean of $0.04 \%$ of total brain volume.

The MEA is readily distinguished from surrounding structures as having moderately dense cell packing (fig. 3 ). The MEA is located at the ventral edge in a coronal section and is bordered medially by the optic tract and laterally by the less densely cell packed anterior cortical amygdala nucleus and the basomedial amygdala nucleus. The volume of the MEA ranged from 0.59 to $0.65 \mathrm{~mm}^{3}$ on each side and together account for a mean of $0.15 \%$ of total brain volume. The MEApd was also measured separately as this subregion has been demonstrated to be sexually dimorphic [Hines et al., 1992; Cooke et al., 2003]. The MEApd is readily distinguished from surrounding structures as having a moderately dense cell packing (fig. 3 ). The volume of the MEApd ranged from 0.14 to $0.28 \mathrm{~mm}^{3}$ on each side and together account for a mean of $0.05 \%$ of total brain volume.

The VTA is more difficult to delineate, which is attested by its nomenclature as an area rather than nuclei. Area refers to a region of loosely grouped cells in which discrete cell groups have no discernible boundaries from neighboring cell groups [Bleier et al., 1982]. This is in contrast to nuclei in which discrete boundaries between cell groups are readily delineated. The VTA has most often been delineated in coronal sections as the group of cells medial to the substantia nigra (SN) and medial lemniscus sometimes including the dopaminergic midline nuclei [Oades and Halliday, 1987] and sometimes excluding these nuclei [see Ikemoto, 2007, for a review of VTA delineation and nomenclature; Swanson, 1982]. Because the cell bodies in this area lie in the horizontal plane [Phillipson, 1979], we cut our sections horizontally and distinguished this area using lines drawn between three reference points to frame the area: from the medial lemniscus to the medial terminal nucleus of the accessory optic track to the interpeduncular nucleus [Ikemoto, 2007; Margolis et al., 2012]. However, using this criterion alone for the lateral border may include some of the THir-positive SNc cells that wrap around the medial terminal nucleus of the accessory optic track (MT). Therefore, we also used tract tracing, between the dorsal striatum and $\mathrm{SNc}$, as an additional aid 
Fig. 2. Representative photomicrographs of 40$\mu \mathrm{m}$ coronal sections through the rostral to caudal (a-d and $\mathbf{e}-\mathbf{h})$ extent of the BNST stained with cresyl violet in female $(\mathbf{a}-\mathbf{d})$ and male $(\mathbf{e}-\mathbf{h})$ California mice. The complexity of the BNST is demonstrated through the rostral to caudal axis by cell-dense and cell-sparse parts of the BNST. The BNST and BNSTpr are significantly larger in males compared to females $(\mathrm{p}<0.05)$. Thin solid lines indicate the boundary of BNST. Thin dotted lines indicate the boundary of the posterior dorsal nucleus of the BNST. Scale bars $=500$ $\mu \mathrm{m}$.
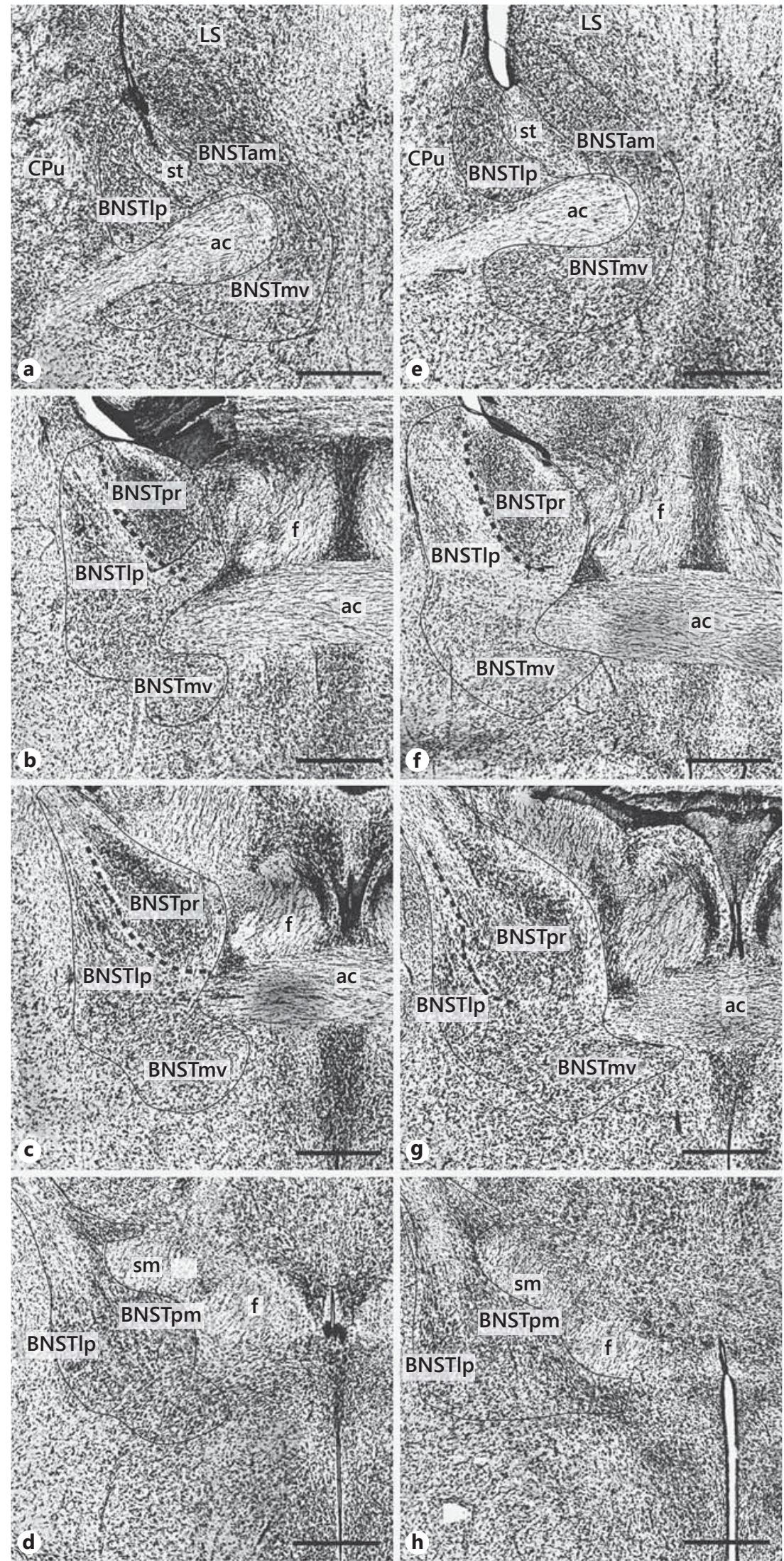

Sexual Dimorphism in the Brain of the Monogamous California Mouse
Brain Behav Evol 2013;81:236-249 DOI: $10.1159 / 000353260$ 
Fig. 3. Representative photomicrographs of $40-\mu \mathrm{m}$ coronal sections of the posterior dorsal MEA stained with cresyl violet in female (a) and male (b) California mice. The MEApd is significantly larger in females compared to males $(\mathrm{p}<0.05)$. Thin solid lines indicate the boundary of the MEApd. Scale bars $=500 \mu \mathrm{m}$.

Fig. 4. Photomicrographs of horizontal sections of the dorsal (a) through ventral (b) aspect of a $0.3-\mu \mathrm{l} \mathrm{BDA}$ injection directed at the dorsal striatum. c Retrograde labeling of cell bodies can be seen on the lateral edge of the SN and at the tip of the arrow on the medial edge of SN in the SNc. d Representative photomicrograph of a horizontal section immunohistochemically reacted for $\mathrm{TH}$. The arrow tip points to the band of TH-ir-positive cells located in the $\mathrm{SNc}$ and used as the lateral boundary for the VTA. Scale bars $=500 \mu \mathrm{m}$.
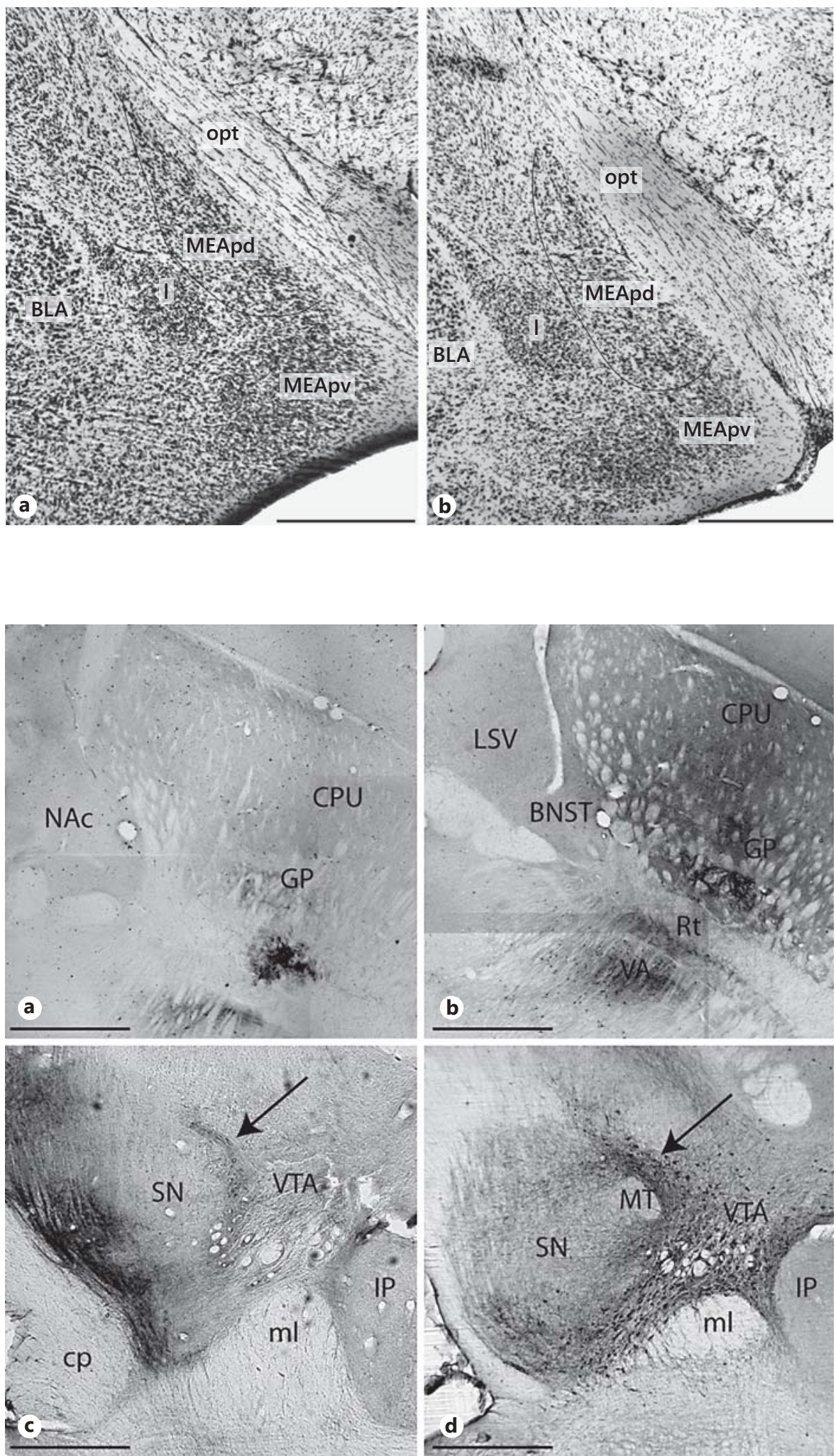

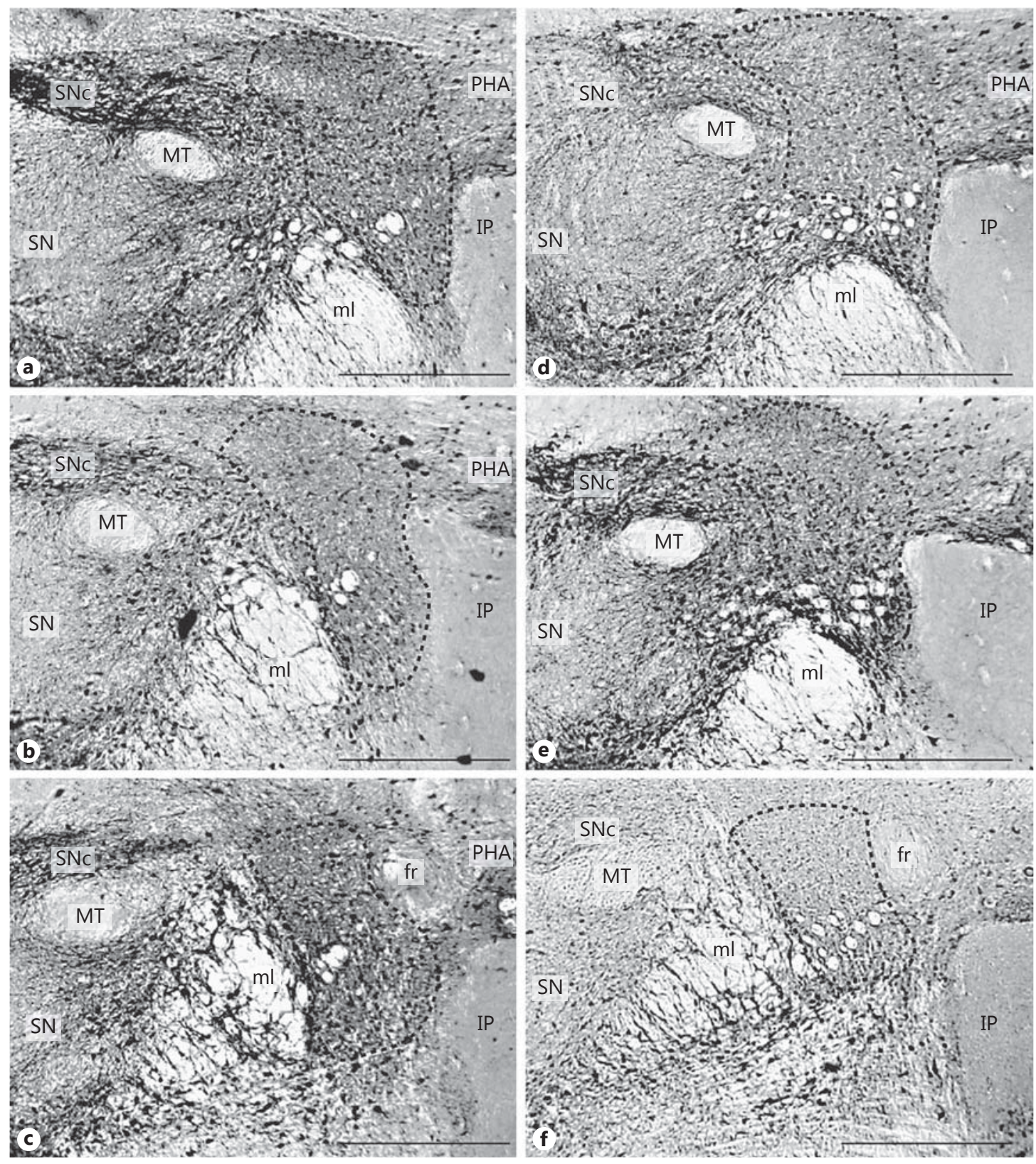

Fig. 5. Representative photomicrographs of $40-\mu \mathrm{m}$ horizontal sections through the dorsal to ventral (a-c and d-f) extent of the VTA immunohistochemically reacted for TH in female (a-c) and male (d-f) California mice. VTA volume and number of TH-ir-positive cells did not differ between females and males. Thin dotted lines indicate the boundary of the VTA. Scale bars $=500 \mu \mathrm{m}$.

to differentiate between VTA and SNc (fig. 4). Connections between the SNc and VTA are somewhat distinct with SNc neurons predominantly receiving projections from the dorsal striatum while VTA neurons predominantly receive projections from the ventral striatum [Joel and Weiner, 2000]. As can be readily observed in figure 4 the band of BDA tracer-labeled cells wraps the MT, as has previously been observed in rats but not mice [Margolis et al., 2012]. However, when TH immunoreacted slices are ob- served the dark band of neurons surrounding the MT is readily delineated and was used in subsequent analysis as the border for VTA. The volume of the VTA ranged from 0.26 to $028 \mathrm{~mm}^{3}$ on each side and together account for a mean of $0.07 \%$ of the total brain volume (fig. 5).

The NAc is readily distinguished as a densely cell-packed, ovoidshaped structure encircling the AC (fig. 6). The NAc is bordered by the less cell-dense caudate putamen on the dorsolateral boundary 
and lateral septal nuclei and very densely cell-packed islands of Calleja major island on the dorsomedial boundary. The ventral boundary of the NAc is delineated by the surrounding very densely cell-packed ventral pallidum, islands of Calleja and ventral pallidum. The volume of the NAc ranged from 1.8 to $1.9 \mathrm{~mm}^{3}$ on each side and together account for a mean of $0.47 \%$ of total brain volume.

\section{Results}

Female and male California mice did not significantly differ in body weight ( mean $\pm \mathrm{SE} \%=32.6 \pm 1.5 \mathrm{~g} ; \sigma^{\prime \prime}=29.8$ $\pm 0.9 \mathrm{~g} ; \mathrm{p}=0.16)$, brain weight in grams $(\%=0.82 \pm$ $\left.0.02 \mathrm{~g} ; \sigma^{x}=0.79 \pm 0.04 \mathrm{~g} ; \mathrm{p}=0.60\right)$, brain volume $(\%=828$ $\pm 24 \mathrm{~mm}^{3} ; \mathrm{o}^{7}=787 \pm 39 \mathrm{~mm}^{3} ; \mathrm{p}=0.40$ ), or percent of

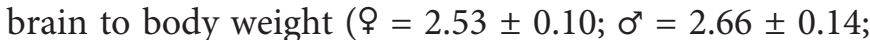
$\mathrm{p}=0.45)$.

\section{Nuclei Volume Comparisons}

Similar to other rodent species, in males the SDNPOA is significantly larger compared to females $[\mathrm{t}(8)=$ 2.904; $\mathrm{p}=0.02$; fig. $7 \mathrm{a}$ ]. Although there is no significant difference in the overall (including all subregions) volume of the MEA between male and female California mice, the MEApd is significantly larger in males compared to females $[t(7)=2.760 ; p=0.03$; fig. $7 a, b]$. There was no significant difference in the overall (including all subregions) volume of the BNST or in the BNSTam volume. However, BNSTpr is significantly larger in males compared to females [ $t(6)=3.003 ; p=0.04$; fig. 7a]. There were no significant differences between female and male California mice in the observed volumes or mean percent of total brain volume for the NAc or VTA (fig. 7b). There is no significant difference in the number of TH-ir-positive cells in the VTA between female and male California mice (data not shown).

\section{Discussion}

While female and male California mice have similar body size and brain volume, our results show that sexual dimorphism in the SDN-POA, BNSTpr and MEApd persist in this monogamous species. This is the first time a sex difference in the size of the MEApd has been reported for a monogamous species. These nuclei are important nodes in the social behavior network that modulates sexual and aggressive behaviors [Goodson, 2005]. In rodents, sexual dimorphism in copulatory behavior is widespread. For example, lordosis is observed in females but not males in both monogamous and polygynous species
[Beach, 1976; Carter et al., 1987; Northcutt and Lonstein, 2008]. Sex differences in aggression are also strong, although there are intriguing exceptions. For example, in house mice males aggressively defend territories whereas aggressive interactions among females are less frequent [Hurst, 1987]. In contrast, female and male California mice jointly defend a territory and both males and females are readily aggressive with same-sex conspecifics [Ribble and Salvioni, 1990]. Sexual dimorphism in some nuclei, such as the SDN-POA, appears to be correlated with social organization. In contrast, sexual dimorphism in other nuclei like the BNSTpr and MEApd appear to be more evolutionarily conserved (table 1 ).

We found that the SDN-POA is twice as large in male California mice compared to females. Compared to other species with polygynous social organizations, these differences are subtle. In guinea pigs the SDN-POA size is four times larger in males than in females [Hines et al., 1985] and an SND-POA cannot even be discriminated in female ferrets [Tobet et al., 1986] or gerbils [Commins and Yahr, 1984]. Although human social organization does not lend itself easily to categorization as monogamous or polygynous, sexual dimorphism in the human SDN-POA resembles that in rodent species with monogamous social organization [Hofman and Swaab, 1989]. Thus, these differences in magnitude do trend towards polygynous species having approximately a 4 -fold difference in SDN-POA size between males and females versus a 2-fold difference in monogamous species. In contrast to the SDN-POA, no such trend is observed in the sex differences in volume of the BNSTpr or MEApd. Indeed, sex differences in BNSTpr size are remarkably consistent across species of rodents with different social organization (about 1.2-1.5 times larger in males than females). Similarly, there is little variation in sexual dimorphism in the MEApd which is typically about 1.4 times larger in males than females. These data underscore the idea, taken from sensory area evolution, that certain regions/areas or networks of areas in the brain may be evolutionarily conserved but modified in a species-specific manner or during the lifetime of the individual [Krubitzer, 2007]. These data suggest that individual nodes in the social decisionmaking network can vary independently of each other.

Intriguingly, size differences in all three of these sexually dimorphic nuclei have previously been demonstrated to be controlled by gonadal hormones. Given that the extent of sexual dimorphism across the SDN-POA, BNSTpr and MEApd can be uncoupled, this suggests that different developmental mechanisms may be activated by hormones in these nuclei. For example, in Mus, testosterone 

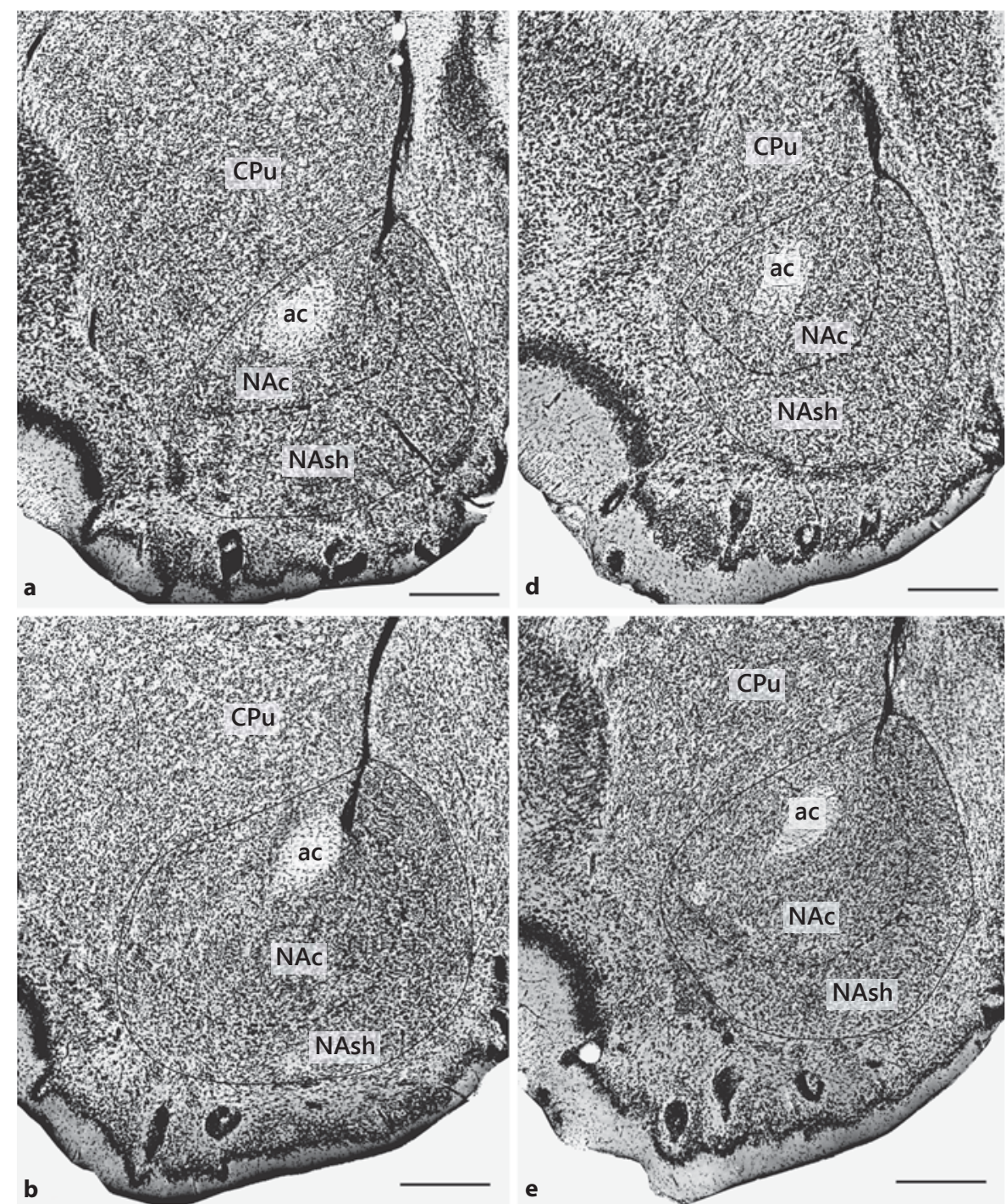

Fig. 6. Representative photomicrographs of 40 - $\mu \mathrm{m}$ coronal sections through the rostral to caudal (a-c and $\mathbf{d}-\mathbf{f}$ ) extent of the NAc stained with cresyl violet in female (ac) and male (d-f) California mice. NAc volume did not differ between female and male California mice. Thin solid lines indicate the boundary of the NAc. Thin dotted lines indicate the boundary of the core and shell subdivisions. Scale bars $=500 \mu \mathrm{m}$.
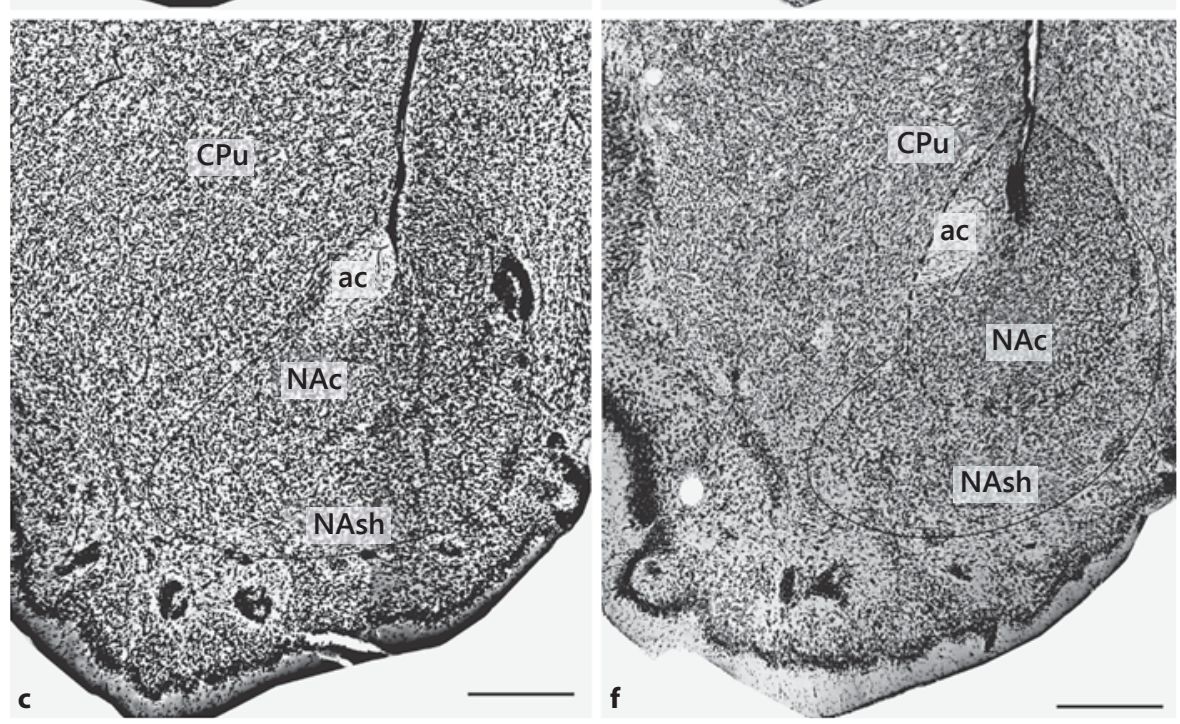

Sexual Dimorphism in the Brain of the Monogamous California Mouse

Brain Behav Evol 2013;81:236-249 

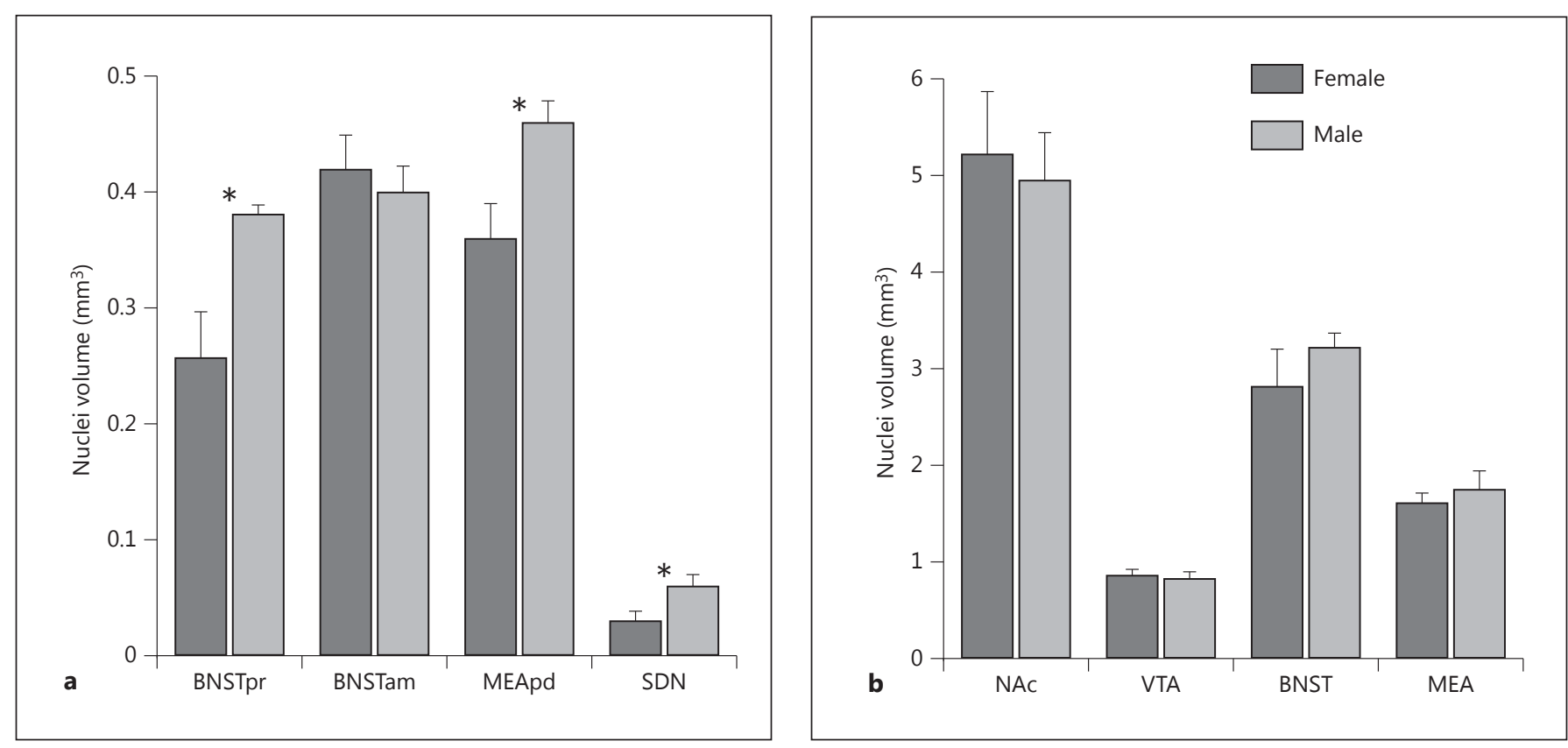

Fig. 7. a Subregion volume comparison. b Nuclei volume comparison. ${ }^{*} \mathrm{p}<0.05$.

has different effects on gene expression in the POA versus the BNST [Xu et al., 2012]. These gene expression profiles could influence processes such as apoptosis, which is known to contribute to sexual dimorphism [Chung et al., 2000; Hsu et al., 2001; Hisasue et al., 2010]. Variation in genetic background is thought to be a major factor influencing differences in sexual dimorphism in different strains of mice [Brown et al., 1999]. The sexual dimorphism in the SDN-POA in rabbits, where females have larger cells compared to males, is intriguing [Bisenius et al., 2006]. However, no large differences exist in mating behaviors in this species. In both rodents and lagomorphs, mounting and thrusting is observed in both males and females while lordosis is observed in females only [Morali and Beyer, 1992; Northcutt and Lonstein, 2008]. Small differences are present such that in contrast to rats, previous sexual experience does not affect mounting behavior in rabbits [Contreras and Beyer, 1979] and SDN-POA lesions in male rabbits as well as hormonal manipulations in female rabbits do alter the pelvic thrusting behavior [Morali et al., 2003]. Thus, the sexual dimorphism in the SDN-POA of rabbits appears to be highly derived and its effects on behavior remain unclear. Intriguingly, in rats the sex difference in volume of the MEApd has been found to be dependent on circulating androgens starting before puberty and continuing into adulthood [Cooke et al., 1999; Cooke and Woolley, 2005]. This effect is thought to be mediated by effects of testosterone on dendritic branching and glial processes [Gomez and Newman, 1991; Rasia-Filho et al., 2002], rather than changes in the number of neuron or glial cells [Cooke and Woolley, 2005; Morris et al., 2007]. In closely related deer mice and white-footed mice, male testosterone levels are between 1.5 and $2.0 \mathrm{ng} / \mathrm{ml}$, whereas male California mice testosterone levels are only $0.5 \mathrm{ng} / \mathrm{ml}$ [Marler et al., 2003]. This suggests that the threshold in testosterone needed to maintain sex differences in MEApd size may be quite low, perhaps $0.5 \mathrm{ng} / \mathrm{ml}$ or lower.

Our findings in the mesolimbic dopamine system are mixed in comparison to previous studies. Similar to previous reports, we did not detect sex differences in the volume of the NAc. In contrast to previous reports in rats [McArthur et al., 2007], we did not observe a difference in either the volume or the number of TH-ir-positive cells in the VTA. Two important features of our study are: (1) the use of tract tracing to help define the borders of the VTA, and (2) the use of horizontal sections of the California mouse brain. Dopamine neurons in the VTA have a caudal to rostral orientation, so horizontal sections maximize the visibility of these cells [Phillipson, 1979; Margolis et al., 2006]. As indicated by its classification as an 'area', the VTA is a difficult region to delineate anatomically. In particular, the lateral border with the SNc is different between mice and rats such that $\mathrm{SNc}$ cells wrap 
around the MT in rats [see fig. 1 in Margolis et al., 2012] but not in mice [see fig. 4 in Chieng et al., 2011]. We observed a similar wrapping of SNc cells around the MT in the California mouse (fig. 4, 5), which more closely resembles the condition in domestic rats than the domestic house mouse. Although most cells in the SNc and VTA cells are $\mathrm{TH}$-ir positive (making distinguishing the boundary difficult based on $\mathrm{TH}$ immunoreactivity) the regions have somewhat distinct connections with $\mathrm{SNc}$ neurons predominantly receiving projections from the dorsal striatum while VTA neurons predominantly receive projections from the ventral striatum [Joel and Weiner, 2000]. Thus, tract tracing was used to confirm that the TH-ir-positive neurons surrounding MT were indeed part of $\mathrm{SNc}$; it therefore helped to delineate the border between SNc and VTA. The VTA is known to be important in regulating motivated behavior [Berridge and Robinson, 1998] and the development of precise landmarks for delineating the VTA in the California mouse will be valuable for future studies.

Most studies examining sex differences in brain morphology have interpreted their findings either through the lens of sex differences in specific mating behaviors (i.e. mounting behavior) or in the context of mating system differences between species (i.e. polygamous vs. monogamous). In Peromyscus, sex differences in FC size appear to be correlated with social system [Kingsbury et al., 2012], but it appears that sex differences in the SDN-
POA, BNSTpr and MEApd are more enduring, and perhaps an ancestral state within mammals. These nuclei are most often considered within the context of sexual behavior. However, the BNST in particular also has important effects on stress responses and, therefore, might contribute to well-described sex differences in physiological responses to stress [Ter Horst et al., 2009]. For example, social stress in California mice induces a transient increase in corticosterone in females [Trainor et al., 2013] but an enduring increase in baseline corticosterone in males [Trainor et al., 2011]. Social stress in California mice also induces social withdrawal behavior in females but not males [Trainor et al., 2011]. Overall, our data suggest that sexual dimorphism in certain brain structures persists across species with different types of social organization. Thus, we propose that the specific effects (i.e. region size, cell size, neuropeptides, etc.) of the hormonal milieu and specific social and reproductive systems have a more complex relationship than previously suggested by a division based on any one aspect alone.

\section{Acknowledgements}

We wish to thank Dahn Nguyen for assistance with histological processing. We also wish to thank Jennifer Jahncke for contributing to these experiments. This work was supported by a National Institutes of Health grant to Brian C. Trainor (R01MH85069-02).

\section{References}

-Alexander BM, Skinner DC, Roselli CE (2011): Wired on steroids: sexual differentiation of the brain and its role in the expression of sexual partner preferences. Front Endocrinol (Lausanne) 2:42.

-Alheid GF, Beltramino CA, De Olmos JS, Forbes MS, Swanson DJ, Heimer L (1998): The neuronal organization of the supracapsular part of the stria terminalis in the rat: the dorsal component of the extended amygdala. Neuroscience 84:967-996.

Allen LS, Gorski RA (1990): Sex difference in the bed nucleus of the stria terminalis of the human brain. J Comp Neurol 302:697-706.

-Aragona BJ, Liu Y, Curtis JT, Stephan FK, Wang Z (2003): A critical role for nucleus accumbens dopamine in partner-preference formation in male prairie voles. J Neurosci 23:34833490.

Arendash GW, Gorski RA (1983): Effects of discrete lesions of the sexually dimorphic nucleus of the preoptic area or other medial preoptic regions on the sexual behavior of male rats. Brain Res Bull 10:147-154.
Berdoy MJP, Drickhamer LC (2007): Comparative social organisation and life history of rattus and mus; in Wolff JO, Sherman PW (eds): Rodent Societies: An Ecological and Evolutionarly Perspective. Chicago, Chicago University Press, pp 380-382.

Berridge KC, Robinson TE (1998): What is the role of dopamine in reward: hedonic impact, reward learning, or incentive salience? Brain Res Brain Res Rev 28:309-369.

Bester-Meredith JK, Marler CA (2003): Vasopressin and the transmission of paternal behavior across generations in mated, cross-fostered Peromyscus mice. Behav Neurosci 117:455463.

Bisenius ES, Veeramachaneni DN, Sammonds GE, Tobet S (2006): Sex differences and the development of the rabbit brain: effects of vinclozolin. Biol Reprod 75:469-476.

Bleier R, Byne W, Siggelkow I (1982): Cytoarchitectonic sexual dimorphisms of the medial preoptic and anterior hypothalamic areas in guinea pig, rat, hamster and mouse. J Comp Neurol 212:118-130.
Brown AE, Mani S, Tobet SA (1999): The preoptic area/anterior hypothalamus of different strains of mice: sex differences and development. Brain Res Dev Brain Res 115:171-182.

Carleton M, Musser G (1984): Muroid rodents; in: Anderson S, Jones JJ (eds): Orders and Families of Recent Mammals of the World. New York, John Wiley and Sons, pp 189-379.

Carter CS, DeVries AC, Getz LL (1995): Physiological substrates of mammalian monogamy: the prairie vole model. Neurosci Biobehav Rev 19:303-314.

-Carter CS, Witt DM, Auksi T, Casten L (1987): Estrogen and the induction of lordosis in female and male prairie voles (microtus-ochrogaster). Horm Behav 21:65-73.

Chauke M, Malisch JL, Robinson C, de Jong TR, Saltzman W (2011): Effects of reproductive status on behavioral and endocrine responses to acute stress in a biparental rodent, the California mouse (Peromyscus californicus). Horm Behav 60:128-138.
Sexual Dimorphism in the Brain of the Monogamous California Mouse 
Chieng B, Azriel Y, Mohammadi S, Christie MJ (2011): Distinct cellular properties of identified dopaminergic and gabaergic neurons in the mouse ventral tegmental area. J Physiol 589:3775-3787.

-Chung WC, Swaab DF, De Vries GJ (2000): Apoptosis during sexual differentiation of the bed nucleus of the stria terminalis in the rat brain. J Neurobiol 43:234-243.

-Commins D, Yahr P (1984): Adult testosterone levels influence the morphology of a sexually dimorphic area in the Mongolian gerbil brain. J Comp Neurol 224:132-140.

-Contreras JL, Beyer C (1979): A polygraphic analysis of mounting and ejaculation in the New Zealand white rabbit. Physiol Behav 23:939943.

-Cooke B, Hegstrom CD, Villeneuve LS, Breedlove SM (1998): Sexual differentiation of the vertebrate brain: principles and mechanisms. Front Neuroendocrinol 19:323-362.

-Cooke BM, Breedlove SM, Jordan CL (2003): Both estrogen receptors and androgen receptors contribute to testosterone-induced changes in the morphology of the medial amygdala and sexual arousal in male rats. Horm Behav 43:336-346.

Cooke BM, Tabibnia G, Breedlove SM (1999): A brain sexual dimorphism controlled by adult circulating androgens. Proc Natl Acad Sci USA 96:7538-7540.

Cooke BM, Woolley CS (2005): Sexually dimorphic synaptic organization of the medial amygdala. J Neurosci 25:10759-10767.

-Cushing BS, Wynne-Edwards KE (2006): Estrogen receptor-alpha distribution in male rodents is associated with social organization. J Comp Neurol 494:595-605.

de Jong TR, Chauke M, Harris BN, Saltzman W (2009): From here to paternity: neural correlates of the onset of paternal behavior in California mice (Peromyscus californicus). Horm Behav 56:220-231.

$\checkmark$ De Jonge FH, Louwerse AL, Ooms MP, Evers P, Endert E, Van De Poll NE (1989): Lesions of the SDN-POA inhibit sexual behavior of male Wistar rats. Brain Res Bull 23:483-492.

$\checkmark$ De Vries GJ, Boyle PA (1998): Double duty for sex differences in the brain. Behav Brain Res 92: 205-213.

De Vries GJ, Sodersten P (2009): Sex differences in the brain: the relation between structure and function. Horm Behav 55:589-596.

del Abril A, Segovia S, Guillamon A (1987): The bed nucleus of the stria terminalis in the rat: regional sex differences controlled by gonadal steroids early after birth. Brain Res 32:295300.

Forlano PM, Woolley CS (2010): Quantitative analysis of pre- and postsynaptic sex differences in the nucleus accumbens. J Comp Neurol 518:1330-1348.

Franklin BJ, Paxinos G (2007): The Mouse Brain in Stereotaxic Coordinates, ed 3. Waltham, Academic Press.
Frazier CRM, Trainor BC, Cravens CJ, Whitney TK, Marler CA (2006): Paternal behavior influences development of aggression and vasopressin expression in male California mouse offspring. Horm Behav 50:699-707.

Fuxjager MJ, Marler CA (2010): How and why the winner effect forms: influences of contest environment and species differences. Behav Ecol 21:37-45.

Getz LL, McGuire B, Pizzuto T, Hofmann JE, Frase B (1993): Social organization of the prairie vole (microtus ochrogaster). J Mammal 74:44-58.

Gleason ED, Holschbach MA, Marler CA (2012): Compatibility drives female preference and reproductive success in the monogamous California mouse (Peromyscus californicus) more strongly than male testosterone measures. Horm Behav 61:100-107.

Goodson JL (2005): The vertebrate social behavior network: evolutionary themes and variations. Horm Behav 48:11-22.

Gorski RA, Harlan RE, Jacobson CD, Shryne JE, Southam AM (1980): Evidence for the existence of a sexually dimorphic nucleus in the preoptic area of the rat. J Comp Neurol 193: 529-539.

Gubernick DJ, Sengelaub DR, Kurz EM (1993): A neuroanatomical correlate of paternal and maternal behavior in the biparental California mouse (Peromyscus californicus). Behav Neurosci 10:194-201.

Hines M, Allen LS, Gorski RA (1992): Sex differences in subregions of the medial nucleus of the amygdala and the bed nucleus of the stria terminalis of the rat. Brain Res 579: 321-326.

Hines M, Davis FC, Coquelin A, Goy RW, Gorski RA (1985): Sexually dimorphic regions in the medial preoptic area and the bed nucleus of the stria terminalis of the guinea pig brain: a description and investigation of their relationship to gonadal steroids in adulthood. J Neurosci 5:40-47.

Hisasue S, Seney ML, Immerman E, Forger NG (2010): Control of cell number in the bed nucleus of the stria terminalis of mice: role of testosterone metabolites and estrogen receptor subtypes. J Sex Med 7:1401-1409.

Hofman MA, Swaab DF (1989): The sexually dimorphic nucleus of the preoptic area in the human brain: a comparative morphometric study. J Anat 164:55-72.

Holmes MM, Goldman BD, Forger NG (2008): Social status and sex independently influence androgen receptor expression in the eusocial naked mole-rat brain. Horm Behav 54:278285.

Houtsmuller EJ, Brand T, de Jonge FH, Joosten RN, van de Poll NE, Slob AK (1994): SDN-POA volume, sexual behavior, and partner preference of male rats affected by perinatal treatment with ATD. Physiol Behav 56:535-541.

Howard V, Reed MG (2005): Unbiased Stereology: Three-Dimensional Measurement in Microscopy. New York, Garland Sciences/BIOS Scientific.
Hsu HK, Yang RC, Shih HC, Hsieh YL, Chen UY, Hsu C (2001): Prenatal exposure of testosterone prevents SDN-POA neurons of postnatal male rats from apoptosis through NMDA receptor. J Neurophysiol 86:2374-2380.

Hughes SW (2005): Archimedes revisited: a faster, better, cheaper method of accurately measuring the volume of small objects. Phys Educ 40:468-474.

Hurst JL (1987): Behavioral variation in wild house mice Mus domesticus Rutty: a quantitative assessment of female social-organization. Anim Behav 35:1846-1857.

Hutchins M (2004): Mammals and humans: mammalian invasives and pests; in Kleiman V, Geist M, McDade (eds): Grzimek's Animal Life Encyclopedia, ed 2. New York, Thomsan \& Gale, pp 182-193.

-Ikemoto S (2007): Dopamine reward circuitry: two projection systems from the ventral midbrain to the nucleus accumbens-olfactory tubercle complex. Brain Res Rev 56:27-78.

Jannett FJ (1982): Nesting patterns of adult voles, Microtus montanus, in field populations. J Mammal 63:495-498.

Joel D, Weiner I (2000): The connections of the dopaminergic system with the striatum in rats and primates: an analysis with respect to the functional and compartmental organization of the striatum. Neuroscience 96:451-474.

Ju G, Swanson LW (1989): Studies on the cellular architecture of the bed nuclei of the stria terminalis in the rat. I. Cytoarchitecture. J Comp Neurol 280:587-602.

Kalcounis-Rueppell MC, Petric R, Briggs JR, Carney C, Marshall MM, Willse JT, Rueppell O, Ribble DO, Crossland JP (2010): Differences in ultrasonic vocalizations between wild and laboratory California mice (Peromyscus californicus). PLoS One 5:e9705.

Karlen SJ, Krubitzer L (2006): Phenotypic diversity is the cornerstone of evolution: variation in cortical field size within short-tailed opossums. J Comp Neurol 499:990-999.

Karlen SJ, Krubitzer L (2009): Effects of bilateral enucleation on the size of visual and nonvisual areas of the brain. Cereb Cortex 19:13601371.

Kelley DB (1986): The genesis of male and female brains. Trends Neurosci 9:499-502.

Kingsbury MA, Gleason ED, Ophir AG, Phelps SM, Young LJ, Marler CA (2012): Monogamous and promiscuous rodent species exhibit discrete variation in the size of the medial prefrontal cortex. Brain Behav Evol 80:4-14.

Krubitzer L (2007): The magnificent compromise: cortical field evolution in mammals. Neuron 56:201-208.

Lambert KG, Franssen CL, Bardi M, Hampton JE, Hainley L, Karsner S, Tu EB, Hyer MM, Crockett A, Baranova A, Ferguson T, Ferguson T, Kinsley CH (2011): Characteristic neurobiological patterns differentiate paternal responsiveness in two Peromyscus species. Brain Behav Evol 77:159-175. 
Margolis EB, Lock H, Hjelmstad GO, Fields HL Dades RD, Halliday GM (1987): Ventral tegmen(2006): The ventral tegmental area revisited: is there an electrophysiological marker for dopaminergic neurons? J Physiol 577:907924.

-Margolis EB, Toy B, Himmels P, Morales M, Fields HL (2012): Identification of rat ventral tegmental area GABAergic neurons. PLoS One 7:e42365.

- Mayhew TM, Mwamengele GL, Dantzer V (1990): Comparative morphometry of the mammalian brain: estimates of cerebral volumes and cortical surface areas obtained from macroscopic slices. J Anat 172:191-200.

-McArthur S, McHale E, Gillies GE (2007): The size and distribution of midbrain dopaminergic populations are permanently altered by perinatal glucocorticoid exposure in a sex- region- and time-specific manner. Neuropsychopharmacology 32:1462-1476.

Morali G, Asuncion Pia Soto M, Luis Contreras J, Arteaga M, Gonzalez-Vidal MD, Beyer C (2003): Detailed analysis of the male copulatory motor pattern in mammals: Hormonal bases. Scand J Psychol 44:279-288.

Morali G, Beyer C (1992): Motor aspects of masculine sexual-behavior in rats and rabbits. Adv Stud Behav 21:201-238.

-Morris JA, Jordan CL, Breedlove SM (2008b): Sexual dimorphism in neuronal number of the posterodorsal medial amygdala is independent of circulating androgens and regional volume in adult rats. J Comp Neurol 506: 851-859.

Morris JA, Jordan CL, King ZA, Northcutt KV, Breedlove SM (2008a): Sexual dimorphism and steroid responsiveness of the posterodorsal medial amygdala in adult mice. Brain Res 11190:115-121.

Murphy GM Jr (1986): The human medial amygdaloid nucleus: no evidence for sex difference in volume. Brain Res 365:321-324.

Newman S (1999): The medial extended amygdala in male reproductive behavior: a node in the mammalian social behavior network. Ann NY Acad Sci 877:242-257.

Northcutt KV, Lonstein JS (2008): Sex differences and effects of neonatal aromatase inhibition on masculine and feminine copulatory potentials in prairie voles. Horm Behav 54:160-169.

Northcutt KV, Wang Z, Lonstein JS (2007): Sex and species differences in tyrosine hydroxylasesynthesizing cells of the rodent olfactory extended amygdala. J Comp Neurol 500:103-115.

Nowak R (1999) Walker's Mammals of the World. Baltimore, The Johns Hopkins University Press.

O'Connell LA, Hofmann HA (2011): The vertebrate mesolimbic reward system and social behavior network: a comparative synthesis. J Comp Neurol 519:3599-3639.

O'Connell LA, Hofmann HA (2012): Evolution of a vertebrate social decision-making network. Science 336:1154-1157. tal (A10) system: neurobiology. 1. Anatomy and connectivity. Brain Res 434:117-165.

Paredes RG, Baum MJ (1995): Altered sexual partner preference in male ferrets given excitotoxic lesions of the preoptic area anterior hypothalamus. J Neurosci 15:6619-6630.

Paredes RG, Nakagawa Y, Nakach N (1998): Lesions of the medial preoptic area/anterior hypothalamus (MPOA/AH) modify partner preference in male rats. Brain Res 813:1-8.

Parker S (1990) Grzimek's Encyclopedia of Mammals. New York, McGraw-Hill Publishing.

Paxinos G, Watson C (1982): The Rat Brain in Stereotaxic Coordinates. Waltham, Academic Press.

Paxinos G, Watson C, Carrive P, Kirkcaldie M, Ashwell KWS (2008): The Chemoarchitectonic Atlas of the Rat Brain, ed 2. London, Academic Press.

Phillipson OT (1979): A Golgi study of the ventral tegmental area of Tsai and interfascicular nucleus in the rat. J Comp Neurol 187:99-115.

Reimer JD, Petras ML (1967): Breeding structure of house mouse Mus musculus in a population cage. J Mammal 48:88-99.

Ribble DO (1991): The monogamous mating system of Peromyscus californicus as revealed by DNA fingerprinting. Behav Ecol Sociobiol 29: 161-166.

Ribble DO, Salvioni M (1990): Social organization and nest coocupancy in Peromyscus californicus, a monogamous rodent. Behav Ecol Sociobiol 26:9-15.

Roselli CE, Larkin K, Resko JA, Stellflug JN, Stormshak F (2004): The volume of a sexually dimorphic nucleus in the ovine medial preoptic area/anterior hypothalamus varies with sexual partner preference. Endocrinology 145:478-483.

Scherle W (1970): A simple method for volumetry of organs in quantitative stereology. Mikroskopie 26:57-60.

Shapiro LE, Leonard CM, Sessions CE, Dewsbury DA, Insel TR (1991): Comparative neuroanatomy of the sexually dimorphic hypothalamus in monogamous and polygamous voles. Brain Res 541:232-240.

-Silva AL, Fry WHD, Sweeney C, Trainor BC (2010): Effects of photoperiod and experience on aggressive behavior in female California mice. Behav Brain Res 208:528-534.

Sodersten P (1987): How different are male and female brains? Trends Neurosci 10:197-198.

Swanson LW (1982): The projections of the ventral tegmental area and adjacent regions: a combined fluorescent retrograde tracer and immunofluorescence study in the rat. Brain Res Bull 9:321-353.

Ter Horst GJ, Wichmann R, Gerrits M, Westenbroek C, Lin Y (2009): Sex differences in stress responses: focus on ovarian hormones. Physiol Behav 97:239-249.
Tobet SA, Zahniser DJ, Baum MJ (1986): Differentiation in male ferrets of a sexually dimorphic nucleus of the preoptic/anterior hypothalamic area requires prenatal estrogen. Neuroendocrinology 44:299-308.

- Trainor BC, Crean KK, Fry WHD, Sweeney C (2010a): Activation of extracellular signalregulated kinases in social behavior circuits during resident-intruder aggression tests. Neuroscience 165:325-336.

- Trainor BC, Pride MC, Villalon Landeros R, Knoblauch NW, Takahashi EY, Silva AL, Crean KK (2011): Sex differences in social interaction behavior following social defeat stress in the monogamous California mouse (Peromyscus californicus). PLoS One 6:e17405.

Trainor BC, Rowland MR, Nelson RJ (2007): Photoperiod affects estrogen receptor alpha, estrogen receptor beta, and aggressive behavior. Eur J Neurosci 26:207-218.

- Trainor BC, Takahashi EY, Campi KL, Florez SA, Greenberg GD, Laman-Maharg A, Laredo SA, Orr VN, Silva AL, Steinman MQ (2013): Sex differences in stress-induced social withdrawal: independence from adult gonadal hormones and inhibition of female phenotype by corncob bedding. Horm Behav 63: 543-550.

- Trainor BC, Takahashi EY, Silva AL, Crean KK, Hostetler C (2010b): Sex differences in hormonal responses to social conflict in the monogamous California mouse. Horm Behav 58: 506-512.

-Viglietti-Panzica C, Panzica GC, Fiori MG, Calcagni M, Anselmetti GC, Balthazart J (1986): A sexually dimorphic nucleus in the quail preoptic area. Neurosci Lett 64:129-134.

Wade J, Arnold AP (2004): Sexual differentiation of the zebra finch song system. Ann NY Acad Sci 1016:540-559.

-Wang Z, Ferris CF, De Vries GJ (1994): Role of septal vasopressin innervation in paternal behavior in prairie voles (Microtus ochrogaster). Proc Natl Acad Sci USA 91:400-404.

Weckerly FW (1998): Sexual-size dimorphism: influence of mass and mating systems in the most dimorphic mammals. J Mammal 79:3352.

Weibel ER (1979): Stereological Methods, Volume 1: Practical Methods for Biological Morphometry. London, Academic Press.

Wetherbee DK (1961): Investigations into the life history of the common coturnix. Am Mid Nat 65:168-186.

Wissman AM, May RM, Woolley CS (2012): Ultrastructual analysis of sex differences in nucleus accumbens synaptic connectivity. Brain Struct Funct 217:181-190.

-Wu MV, Manoli DS, Fraser EJ, Coats JK, Tollkuhn J, Honda S, Harada N, Shah NM (2009): Estrogen masculinizes neural pathways and sexspecific behaviors. Cell 139:61-72.

- Xu X, Coats JK, Yang CF, Wang A, Ahmed OM, Alvarado M, Izumi T, Shah NM (2012): Modular genetic control of sexually dimorphic behaviors. Cell 148:596-607.
Sexual Dimorphism in the Brain of the Monogamous California Mouse
Brain Behav Evol 2013;81:236-249 DOI: 10.1159/000353260 